\title{
Investigation of Internet Addiction Levels of Physical Education Teachers
}

\author{
Çă̆rı Hamdi Erdoğan ${ }^{1 \rtimes}$ \\ Ramazan Topuz ${ }^{2}$ iD \\ 'Ministry of Education, Şehit Ahmet Cihan Kilci Middle School, Kayseri, Turkey. \\ Email:erdoganhamdi@hotmail.com Tel:+903524271213 \\ ${ }^{2}$ Selçuk University, Faculty of Sport Sciences, Konya, Turkey. \\ Emanl.ramaran topuza@hotmanlcom Tel-+903399411606
}

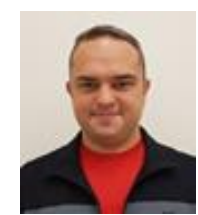

( Corresponding Author)

\section{Abstract}

The aim of this study is to examine the internet addiction levels of physical education teachers. In the study, the descriptive survey method was used, which aimed at revealing the existing situation. The research group was comprised of 356 physical education teachers actively working at the public schools of Kayseri province in the 2019-2020 education year. In the study, Personal Information Form and Internet Addiction Scale were used as the data collection tools. SPSS program was used for the analysis of the data. According to the research results, internet addiction levels of physical education teachers was determined as "displaying no symptoms", and according to this result, the internet addiction levels of the physical education teachers was interpreted as "low level". Additionally, it was determined that there were statistically significant differences in the internet addiction levels of physical education teachers concerning age, marital status, professional experience, monthly income perception, school type, and school location; however, there was statistically no significant difference concerning the gender and sports branch.

Keywords: Physical education, Sports, Psychology, Teacher, Internet, Addiction.

Citation | Cağrı Hamdi Erdoğan; Ramazan Topuz (2020). Investigation of Internet Addiction Levels of Physical Education Teachers. Asian Journal of Education and Training, 6(2): 169-175. History:

Received: 16 December 2019

Revised: 27 January 2020

Accepted: 2 March 2020

Published: 23 March 2020

Licensed: This work is licensed under a Creative Commons

Licensed: This work is lice
Attribution 3.0 License (cc) E

Publisher: Asian Online Journal Publishing Group
Acknowledgement: Both authors contributed to the conception and design of the study.

Funding: This study received no specific financial support.

Competing Interests: The authors declare that they have no conflict of interests.

Transparency: The authors confirm that the manuscript is an honest, accurate, and transparent account of the study was reported; that no vital features of the study have been omitted; and that any discrepancies from the features of the study have been omitted;
study as planned have been explained.

Ethical: This study follows all ethical practices during writing.

\section{Contents}

1. Introduction

2. Method

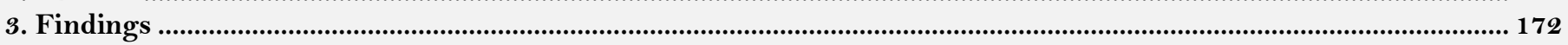

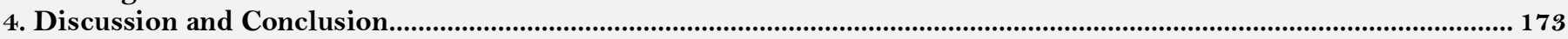

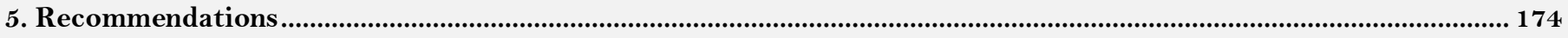

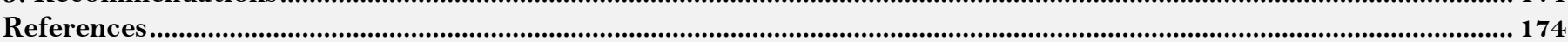




\section{Contribution of this paper to the literature}

This study contributes to the existing literature by examining the internet addiction levels of physical education teachers.

\section{Introduction}

Internet is a network that connects one or more technological tools such as phones, computers and tablets, enabling the communication (Oztoprak, 2001). With the rapidly developing technology in today's world, the use of internet has become an indispensable part of our lives (Arisoy, 2009). Its active use in school, business and community life has rendered it a mandatory need in each passing day. The use of the internet has become an obligation for the daily activities in all areas ranging from official transactions to providing services for the entire nation. Additionally, the internet has become irreplaceable in terms of its funny and enjoyable use (Günüç, 2009).

In each passing day, owing to its conveniences and opportunities, internet technology has become an indispensable part of our lives just like the television and computer. The factors underlying this phenomenon are the ease of access, variety of services and opportunities offered by the internet and similar tools, having a flexible technology, powerful visuals, and being open to interaction (Esen, 2010). With the internet, users have met a new channel where they can easily access all kinds of information, long distances do not matter and quick communication with others is possible. The internet allows individuals to easily perform all kinds of activities in accordance with their tastes and desires without having too much control (Aydoğdu, 2003).

Globalizing the world and eliminating borders, the internet provides an opportunity for people living in numerous different cities, countries, and even continents to communicate quickly and economically (Kaya., 2011). Eliminating the borders in global and local terms, the internet opens up new ways of communication and interaction, and by becoming a medium, where more ordinary transactions are completed in each passing day, it draws the boundaries of the daily life. On the other hand, although it offers opportunities to explore the social life, the internet threatens to damage the fundamental values of interpersonal relationships and society (Denizci, 2009).

Internet use is seen as a way of dealing with some kind of stress. People, who are intensely distressed, anxious, and excited, spend time on the computer and provide distraction for themselves through internet, thus, they can decrease their internal problems or the severity of these problems (Ogel, 2010). Internet users, especially young people, are influenced by all kinds of information and value, which are rapidly spreading through this virtual world. With its anonymous and interactivebasics, the internet becomes an element of everyday life and quickly engulfs people (Derin, 2013; Kır, 2008).

The effects of the internet in the community structure and individual lives of people are increasing in proportion to the developmental speed of the internet. While many experiences and individuals living in crowds were unnoticed or hidden in a mess, today any point or individual has become accessible in the world through the internet (Arisoy, 2009; Tamam, 2009). The internet is a multidimensional concept that has different meanings for everyone, without a fixed function. The internet can be seen as an electronic library for some, a newspaper for some, and as a political propaganda medium for others. In other words, the function of the internet is completely shaped depending on the user. Examining the previous studies, it can be stated that internet use is predominantly social and the internet is seen as a means of communication. In this context, the internet offers much more participation compared to other mass media (Bayraktutan, 2005).

Having access to the internet, people create a field of dominance of their own and can design and control this field according to their own wishes. In this world, which they create for themselves, they can even forget the problems that are difficult to overcome and evade from the troubles of daily life through this means. An individual, who lives alone in his/her own world and daily life, can relieve his/her loneliness with the internet. Additionally, thanks to the internet, he/she can completely differentiate his/her identity and gain approvals by pretending to be someone else. Individuals search for environments in which they can be approved and appreciated under any circumstances. While this quest for approval and appreciation is a result of intensive and fast life in large cities, it can emerge from the lack of sufficient satisfaction in social life in smaller cities. In fact, the virtual world offers us the opportunity to bring together the impossible imaginary and the existing truth (Dikme, 2014).

A person's inability to stop using an item or behavior is defined as addiction. In each passing day, certain changes occur in one's daily activities and routines due to addiction, with a gradual deterioration in the functionality of life. Certain symptoms of addition are seen as being overly engaged with a substance or behavior, being unable to control oneself about the use of this behavior or substance, worrying other people about oneself as losing control, and continuing to use despite its harmful consequences (Egger \& Rauterberg, 1996).

While becoming addicted, both fomentation and ambition provides a pleasure and a sense of fun at the same time. This condition remains a memory in the prefrontal lobe of the brain. This situation turns into a need after a while, resulting in overuse and addiction. Besides its effects on the brain structure, genetic, psychosocial, and environmental factors are also effective in the process of becoming addicted, which is a chronic problem (Ŭgurlu, Sengül, \& Sengül, 2012).

In the initial definitions, addiction was evaluated only as the drug addiction. However, with the development of technology, some behavioral changes have also started to be mentioned in the concept of addiction (Cengizhan, 2005). Examining the literature on addiction, it is seen that addiction is studied in two main topics as behavioral addiction and drug addiction. In drug addiction, certain issues are addressed such as heroin, alcohol, cigarettes, coffee, etc., while in behavioral addiction it is discussed whether a certain behavior is displayed in an abnormal frequency, addressing the problems that the individual encounters in one's personal and social life (Karaman \& Kurtoğlu, 2009).

Addiction is a situation that occurs when a substance is taken with repeated doses and continuously increasing amounts, without eliminating the symptoms of an organic disorder; it is an unavoidable and severe situation of desire that creates some mental and physical disorders in the person in case of discontinuation of substance use (Turnalar, 2008; Ziyalar, 1999).

Addiction is an irresistible request to repeat a constant action, although it harms one's own mental and physical health or social life (Kırık, Arslan, Karaman, \& Çetinkaya, 2015). Addiction has emerged as an important 
biopsychosocial problem since people realized that certain substances changed their mental state and made them feel different, though temporarily (Beyazyürek \& Satır, 2000).

In our age, which can be called as the technology era, the use of computers and internet networks has taken its place among the indispensables of the human life. Although the main purpose of the internet is to reach information easily, cheaply, quickly and securely and facilitate communication, since it increasingly becomes widespread with an unpredictable speed and due to the ease of access, it started to result in a pathological overuse, which can be called as a new type of addiction (Arisoy, 2009).

The internet addiction, which was added into the literature as a type of behavioral addictions, was resulted from certain facts of internet such as shifting from the technical or academic area to the actual area, becoming a source, where every single person can have an access to, and widening the horizons in communication. Internet addiction is a type of addiction that can be seen at all ages and genders (Oztürk, Odabaşıŏlu, Eraslan, Genç, \& Kalyoncu, 2007).

Internet addiction is defined as the inability to prevent the tendency to use the internet, considering the time spent without internet as insignificant and worthless, observing excessive anger, temper, and aggression on an individual when he/she has no access to internet, and influencing the family, professional, and social life of an individual (Young, 2004). In general terms, internet addiction is expressed as the use of internet too intensively to control, which, in turn, results in the inability to fulfill one's responsibilities and having problems in one's social relations (Zorbaz, 2013).

Considering its structure and the services it offers, the internet has the ability to be used widely in education field, since it is the most valuable learning environment for the people of the internet information societies (Kaya, 2006). The information share is also employed through the internet. It is a huge network that is growing in line with the demands of individuals from all of the world to store, share and access information. The internet has become a virtual library where everyone can have an access to unlimited information from anywhere (Yilmaz \& Horzum, 2005). In this context, it is important for the teachers to use the internet efficiently in education. In order to encourage the teachers to use the internet efficiently, it is of significance to examine their internet addiction levels, which will contribute to the field. This study aimed to examine the internet addiction levels of physical education teachers. In addition, the internet addiction levels of physical education teachers were compared based on certain characteristics.

\section{Method}

\subsection{Research Model}

This was a research that was designed in the descriptive survey model. Survey model research studies are defined as the kind of studies, in which information is gathered from a large mass through multiple choice answers determined by the researcher (Fraenkel \& Wallen, 2006).

\subsection{Research Group}

The research group was comprised of 356 physical education teachers who were actively working in the 20192020 education year in public schools in Kayseri province, Turkey, and were randomly selected. Of the physical education teachers in the research group, 124 (34.8\%) were female and $232(65.2 \%)$ were male; $192(53.9 \%)$ were married and $164(46.1 \%)$ were single.

\subsection{Data Collection Tools}

In this study, which was conducted to determine the internet addiction levels of physical education teachers and compare them through certain characteristics, the Personal Information Form and Young Internet Addiction Scale were used as the data collection tools. The Personal Information Form was developed by the researchers in order to determine the demographic characteristics of the physical education teachers in the research group.

The likert-type Internet Addiction Scale, which was developed by Young. (1996) included 20 questions. Bayraktar (2001) translated the scale into Turkish, employing its validity and reliability tests. The reliability of the scale, which was translated into Turkish, was calculated as 0.91 in terms of the Alpha coefficient, and 0.87 in terms of the Spearman-Brown value. The results demonstrated that the scale was reliable.

Internet Addiction Scale, which was translated into Turkish and included 20 questions, is implemented in a likert-type rating. In the scale, the participants are asked to choose one of these multiple choices "Never", "Rarely", "Sometimes", "Often", and "Always". These choices are rated as $0,1,2,3,4$, and 5 points. In the evaluation of the scale, scoring 80 points and over indicates that the participant is "internet addicted", scoring between 50-79 means the participant "has limited symptoms", and scoring 50 and below indicates that the participant "displays no symptoms" (Cakır \& Horzum, 2008).

\subsection{Statistical Analyses}

In the research, SPSS program was used for data analysis. The frequency, percentage, and descriptive statistics of the data obtained from the scale are given in tables. In order to determine the internet addiction levels of the physical education teachers in the research group, certain data such as arithmetic means $(\bar{X})$, standard deviation $(\mathrm{Sd})$, and significance $(\mathrm{p})$ were obtained. It was determined, through the Kolmogorov-Smirnov test, that the internet addiction levels of the physical education teachers in the research group demonstrated a normal distribution $(p>0.05)$. As per the comparisons; t test method was used for paired comparisons for independent groups, and one-way analysis of variance method (ANOVA) was used for multiple comparisons. The significance level was admitted as $\mathrm{p}<0.05$. 


\section{Findings}

Table-1. Distribution of demographic characteristics of the physical education teachers in the research group.

\begin{tabular}{l|c|c|l|c|c}
\hline Gender & $\mathbf{N}$ & $\mathbf{\%}$ & Marital Status & $\mathbf{N}$ & \% \\
\hline Female & 124 & 34,8 & Married & 192 & 53,9 \\
\hline Male & 232 & 65,2 & Single & 164 & 46,1 \\
\hline Age & $\mathrm{N}$ & $\%$ & Professional Experience & $\mathrm{N}$ & $\%$ \\
\hline 20-29 Years old & 122 & 34,3 & 0-9 Years & 144 & 40,4 \\
\hline 30-39 Years old & 154 & 43,3 & $10-19$ Years & 160 & 44,9 \\
\hline 40-49 Years old & 80 & 22,5 & $20-29$ Years & 52 & 14,6 \\
\hline School Type & $\mathrm{N}$ & $\%$ & School Location & $\mathrm{N}$ & $\%$ \\
\hline Secondary School & 168 & 47,2 & Rural & 48 & 13,5 \\
\hline High School & 188 & 52,8 & Urban & 308 & 86,5 \\
\hline Monthly Income Perception & $\mathrm{N}$ & $\%$ & Sport Branch & $\mathrm{N}$ & $\%$ \\
\hline Low & 56 & 15,7 & Individual Sport & 166 & 46,6 \\
\hline Medium & 264 & 74,2 & Team Sport & 190 & 53,4 \\
\hline High & 36 & 10,1 & & &
\end{tabular}

The demographic characteristics of physical education teachers in the research group are presented in Table 1. It was determined that $124(34.8 \%)$ physical education teachers in the research group were female, $232(65.2 \%)$ were male; $192(53.9 \%)$ were married, $164(46.1 \%)$ were single; $122(34.3 \%)$ were in the 20-29 age group, 154 $(43.3 \%)$ were in the $30-39$ age group, and $80(22.5 \%)$ were in the $40-49$ age group. Additionally, $144(40.4 \%)$ physical education teachers in the research group had a professional experience of 0-9 years, 160 (44.9\%) had 10-19 years, and $52(14.6 \%)$ had 20-29 years; $168(47.2 \%)$ of them worked in secondary schools and $188(52.8 \%)$ were working in high schools; $48(13.5 \%)$ of them were working in rural area, while $308(86.5 \%)$ were working in urban areas; the branch of $166(46.6 \%)$ of the physical education teachers was individual sport, while it was team sport for $190(53.4 \%)$ of them; the monthly income perceptions of $56(15.7 \%)$ physical education teachers was low, it was medium for $264(74.2 \%)$ and high for $36(10.1 \%)$.

Table-2. The mean score of the physical education teachers in the research group obtained from the overall internet addiction scale.

\begin{tabular}{c|c|c|c}
\hline Scale & $\mathbf{N}$ & $\bar{X}$ & Sd \\
\hline Internet Addiction Scale & 356 & 31.00 & 17.965 \\
\hline
\end{tabular}

The results concerning the overall internet addiction scale scores of the physical education teachers in the research group are presented in Table 2. As a result of the analysis, physical education teachers in the research group gained $\overline{\mathrm{X}}=31.00$ mean score from the overall internet addiction scale. According to this result, internet addiction of the physical education teachers in the research group was determined as "displaying no symptoms". According to this result, internet addiction of the physical education teachers in the research group can be interpreted as "low level".

Table-3. Comparison of the internet addiction levels of physical education teachers in the research group concerning their gender, marital status, school type, school location, and sport branch.

\begin{tabular}{|c|c|c|c|c|c|c|}
\hline Gender & $\mathbf{N}$ & $\bar{X}$ & Sd & $\mathbf{t}$ & p & Difference \\
\hline Female & 124 & 33.45 & 19.320 & \multirow[t]{2}{*}{1.889} & \multirow[t]{2}{*}{.060} & \multirow[t]{2}{*}{ No } \\
\hline Male & 232 & 29.68 & 17.096 & & & \\
\hline Marital Status & $\mathrm{N}$ & $\overline{\mathrm{X}}$ & $\mathrm{Sd}$ & $\mathrm{t}$ & $\mathrm{p}$ & Difference \\
\hline Married & 192 & 27.19 & 16.381 & \multirow[t]{2}{*}{-4.433} & \multirow[t]{2}{*}{.000} & \multirow[t]{2}{*}{ Yes } \\
\hline Single & 164 & 35.45 & 18.748 & & & \\
\hline School Type & $\mathrm{N}$ & $\overline{\mathrm{X}}$ & $\mathrm{Sd}$ & $\mathrm{t}$ & $\mathrm{p}$ & Difference \\
\hline Secondary School & 168 & 33.36 & 17.462 & \multirow[t]{2}{*}{2.367} & \multirow[t]{2}{*}{.018} & \multirow[t]{2}{*}{ Yes } \\
\hline High School & 188 & 28.88 & 18.189 & & & \\
\hline School Location & $\mathrm{N}$ & $\overline{\mathrm{X}}$ & $\mathrm{Sd}$ & $\mathrm{t}$ & $\mathrm{p}$ & Difference \\
\hline Rural & 48 & 37.04 & 20.668 & \multirow[t]{2}{*}{2.524} & \multirow[t]{2}{*}{.012} & \multirow[t]{2}{*}{ Yes } \\
\hline Urban & 308 & 30.05 & 17.355 & & & \\
\hline Sport Branch & $\mathrm{N}$ & $\overline{\mathrm{X}}$ & $\mathrm{Sd}$ & $\mathrm{t}$ & $\mathrm{p}$ & Difference \\
\hline Individual Sport & 166 & 32.25 & 19.245 & \multirow[t]{2}{*}{1.231} & \multirow[t]{2}{*}{.219} & \multirow[t]{2}{*}{ No } \\
\hline Team Sport & 190 & 29.90 & 16.742 & & & \\
\hline Total & 356 & 31.00 & 17.965 & & & \\
\hline
\end{tabular}

The results concerning the comparisons of internet addiction levels of the physical education teachers in the research group in terms of gender, marital status, school type, school location, and sport branch are given in Table 3. According to the results of the analysis, it was determined that there were statistically significant differences in the internet addiction levels of the physical education teachers concerning marital status, school type, and school location; however, there was statistically no significant difference concerning the gender and sport branch.

It was determined that the internet addiction levels of the married physical education teachers in the research group were statistically significantly lower compared to those of the single ones. Similarly, it was determined that the internet addiction levels of the physical education teachers in the research group working in high schools were statistically significantly lower compared to those working in secondary schools. Additionally, it was determined that the internet addiction levels of physical education teachers working in the schools located in urban areas were statistically significantly lower compared to those working in the schools located in rural areas. 
Table-4. The comparison of the physical education teachers in the research group about their internet addiction levels in terms of age, professional experience, and monthly income perceptions.

\begin{tabular}{|c|c|c|c|c|c|c|}
\hline Age & $\mathbf{N}$ & $\overline{\mathrm{X}}$ & Sd & $\mathbf{F}$ & p & Difference \\
\hline 20-29 Years old (a) & 122 & 35.85 & 16.544 & \multirow{3}{*}{7.366} & \multirow{3}{*}{.001} & \multirow{3}{*}{$\begin{array}{l}\mathrm{b}<\mathrm{a} \\
\mathrm{c}<\mathrm{a}\end{array}$} \\
\hline 30-39 Years old (b) & 154 & 29.16 & 18.403 & & & \\
\hline 40-49 Years old $(\mathrm{c})$ & 80 & 27.12 & 17.806 & & & \\
\hline Professional Experience & $\mathrm{N}$ & $\overline{\mathrm{X}}$ & $\mathrm{Sd}$ & $\mathrm{F}$ & $\mathrm{p}$ & Difference \\
\hline O-9 Years $(\mathrm{x})$ & 144 & 34.22 & 16.751 & \multirow{3}{*}{3.962} & \multirow{3}{*}{.020} & \multirow{3}{*}{$\mathrm{y}<\mathrm{x}$} \\
\hline 10-19 Years $(y)$ & 160 & 28.72 & 18.437 & & & \\
\hline 20-29 Years $(z)$ & 52 & 29.07 & 18.723 & & & \\
\hline Monthly Income Perception & $\mathrm{N}$ & $\overline{\mathrm{X}}$ & $\mathrm{Sd}$ & $\mathrm{F}$ & $\mathrm{p}$ & Difference \\
\hline Low (j) & 56 & 31.25 & 15.493 & \multirow{3}{*}{5.320} & \multirow{3}{*}{.005} & \multirow{3}{*}{$\mathrm{k}<\mathrm{m}$} \\
\hline Medium (k) & 264 & 29.71 & 17.639 & & & \\
\hline $\operatorname{High}(\mathrm{m})$ & 36 & 40.00 & 21.506 & & & \\
\hline Total & 356 & 31.00 & 17.965 & & & \\
\hline
\end{tabular}

The results concerning the comparisons of internet addiction levels of the physical education teachers in the research group in terms of age, professional experience, and monthly income perceptions are given in Table 4 . According to the results of the analysis, it was determined that there were statistically significant differences in the internet addiction levels of the physical education teachers concerning the age, professional experience, and monthly income perceptions.

It was determined that the internet addiction levels of the physical education teachers in the 30-39 age group and in the 40-49 age group were statistically significantly lower compared to those of the 20-29 age group. Similarly, it was determined that the internet addiction levels of the physical education teachers with 10-19 year of professional experience were statistically significantly lower compared to those with 0-9 years of professional experience. In the research group, the physical education teachers with a medium level of monthly income perception were determined to have lower levels of internet addiction compared to those with higher monthly income perception.

\section{Discussion and Conclusion}

In this study, the internet addiction levels of physical education teachers were examined. According to the research results, internet addiction levels of physical education teachers was determined as "displaying no symptoms", and according to this result, the internet addiction levels of the physical education teachers was interpreted as "low level". Additionally, it was determined that there were statistically significant differences in the internet addiction levels of physical education teachers concerning age, marital status, professional experience, monthly income perception, school type, and school location; however, there was statistically no significant difference concerning the gender and sport branch.

The internet addiction level of the physical education teachers was determined as "displaying no symptoms", and accordingly, the addiction level of the physical education teachers was interpreted as "low level". In previous studies conducted by Kutlu, Turgut, and Sinem (2017); Yılmaz., Çinar, and Özyazıcıŏlu (2017); Günay, Öztürk, and Arslantaş (2018) and Yaraşır (2018) it was determined that the internet addiction level of the participants was "low level". This research is in parallel with these previous research concerning the internet addiction level. In other studies conducted by Kılınç and Gündüz (2017) and Sipahi et al. (2019) it was determined that the internet addiction of the participants was at a "high level". The results of this research contradict those of the abovementioned studies.

It was determined that there was statistically no significant difference in the internet addiction levels of the physical education teachers concerning the gender variable. In previous studies conducted by Brenner (1997); Fu, Chan, Wong, and Yip (2010); Balcı and Gülnar (2013) and Anlayışlı and Bulut (2019) it was determined that there was statistically no significant difference in the internet addiction levels of the participants concerning the gender variable. The results of this research are in parallel with the above mentioned studies concerning the gender variable. In some other previous research conducted by Sherer (1997); Morahan-Martin and Schumacher (2000); Poodineh, Barati, Moghadam, Ghanbarzehi, and Balouchi (2016); Karasu (2017); Kutlu et al. (2017); Anll (2018); Günay et al. (2018) and Yaraşır (2018) it was determined that there were statistically significant differences in the internet addiction levels of the participants concerning the gender variable. The results of this study contradict those of the abovementioned research studies concerning the gender variable.

It was determined that there were statistically significant differences in the internet addiction levels of the physical education teachers concerning the age variable. It was determined that the internet addiction level of the 30-39 age group and 40-49 age group were significantly lower compared to that of the 20-29 age group. In studies conducted by Günay et al. (2018) and Hekim et al. (2019) it was determined that there were statistically significant differences in the internet addiction levels of the participants concerning the age variable. This study is in parallel with the mentioned studies concerning the findings about the age variable. In some other studies conducted by Ergin, Uzun, and Bozkurt (2013) and Kutlu et al. (2017) it was determined that there was statistically no significant difference in the internet addiction levels of the participants concerning the age variable. This study contradicts abovementioned studies concerning the findings about the age variable.

It was determined that there were statistically significant differences in the internet addiction levels of the physical education teachers concerning the marital status variable. It was determined that the internet addiction levels of the married physical education teachers were significantly lower compared to those of the single physical education teachers. In studies conducted by Ilhan et al. (2014) and Aslan and Yazicı (2016) it was determined that there was statistically no significant difference in the internet addiction levels of the participants concerning the marital status variable. This study contradicts the mentioned studies concerning the findings about the marital status. 
It was determined that there were statistically significant differences in the internet addiction levels of the physical education teachers concerning the monthly income perception variable. It was determined that the internet addiction levels of the physical education teachers with medium level of monthly income perception were significantly lower compared to those of physical education teachers with low level of monthly income perception. In a study conducted by Yaraşır (2018) it was determined that there were statistically significant differences in the internet addiction levels of the participants concerning the monthly income perception variable. In some other studies, Anl (2018) determined that there was statistically no significant difference in the internet addiction levels concerning the perceived income, and Kisa (2018) concluded the same finding concerning the monthly income. This study contradicts the mentioned studies concerning the findings about the monthly income.

It was determined that there was statistically no significant difference in the internet addiction levels of the physical education teachers concerning the sport branch variable. In a previous study conducted by Can and Tozoğlu (2019) it was determined that there were statistically significant differences in the internet addiction levels of the participants concerning the sport branch variable. This study contradicts the abovementioned research study concerning the findings about sport branch.

According to the results of the research, determining the internet addiction levels of the physical education teachers as "displaying no symptoms" and interpreting it as "low level" can be considered as a positive case. Internet addiction, which is also defined as problematic internet use, is described as a harmful behavior for the educators. That the physical education teachers do not display internet addiction behavior can be evaluated as an important determination for the education. That younger physical education teachers have higher internet addiction levels compared to the old physical education teachers can be considered as an expected result. This result might have been emerged from the fact that individuals born in the 90 s are engaged in the internet more compared to those born in the $80 \mathrm{~s}$ and 70 s. That the single physical education teachers have higher internet addiction levels compared to those of married physical education teachers might be emerging from the fact that they have no marriage responsibility and they are more free in social terms. That the physical education teachers with lower professional experience partially have higher internet addiction levels can also be attributed to their younger age. That the physical education teachers with higher monthly income perception have higher internet addiction levels can be resulted from the possibility that they budget higher figures for the information technology expenditure. That the physical education teachers working in secondary schools have higher internet addiction levels might have resulted from that they cannot communicate sufficiently with their students. That the physical education teachers working in the rural areas have higher internet addiction levels can be resulted from that they have less opportunity for socialization. As per the sport branch and gender variables, they had no impact on the internet addiction levels of the physical education teachers.

\section{Recommendations}

In order to improve the use of internet, conferences and seminars can be organized by the experts for the physical education teachers. The motives behind the internet addiction of teachers regardless of their levels can be investigated through different studies. Similar research studies can be conducted with different research groups to contribute to the literature. It is considered useful that the internet addiction of the physical education teachers be investigated through qualitative research studies.

\section{References}

Anlayışlı, C., \& Bulut, S. N. (2019). A study on internet addiction and depression among high school students due to gender, academic success and internet usage duration. Folklore/Literature, 25(97), 730-743.

Anl, G. (2018). Examining the relationship between interpersonal sensitivity and internet addiction in terms of different variables. $M A N A S$ Journal of Social Studies, 7(1), 103-1 18.

Arisoy, O. (2009). Internet bagimliligi ve tedavisi/internet addiction and its treatment. Current Approaches in Psychiatry, 1(1), 55-67.

Aslan, E., \& Yazıcı, A. (2016). Internet addiction among university students and related sociodemografic factors. Turkish Journal of Clinical Psychiatry, 19(3), 109-117.

Aydoğdu, C. (2003). Television and computers physicological impulses which is over young people. Sakarya University, Institute of Social Sciences, Master's Thesis.

Balcı, Ş., \& Gülnar, B. (2013). Internet addiction among university students and the profile of internet addicts. Selcuk Iletisim, 6(1), 5-22.

Bayraktar, F. (2001). The role of internet usage in the development of adolescents. Ege University Institute of Social Sciences, Master's Thesis.

Bayraktutan, F. (2005). The use of internet in terms of relations between family members. İstanbul University, Institute of Social Sciences, Master's Thesis.

Beyazyürek, M., \& Satır, T. T. (2000). Substance use disorders. The World of Psychiatry, 4(2), 50-56.

Brenner, V. (1997). Psychology of computer use: XLVII. parameters of internet use, abuse and addiction: The first 90 days of the internet usage survey. Psychological Reports, 8O(1), 879-882.

Cakır, B. O., \& Horzum, M. B. (2008). Internet addiction test. Educational Sciences and Practice, 7(13), 87-102.

Can, H., \& Tozoğlu, E. (2019). Examining of university students' internet addiction levels in terms of sports and different variables. Journal of Sports Education, 3(3), 102-118.

Cengizhan, C. (2005). A new dimension in students' computer and internet usage: Internet addiction. Atatürk Faculty of Education Journal of Educational Sciences, 22(2), 83-98.

Denizci, Ö. M. (2009). Internet phenomenon and its socio-psychological effects in the context of information society. Marmara Journal of Communication, 15(2), 47-65.

Derin, S. (2013). High school students internet addiction and subjective well-being. Hacettepe University, Institute of Social Sciences, Master's Thesis.

Dikme, E. (2014). A research on analysis of vocational high school students' internet addiction within the context of various variables. Yeditepe University, Institute of Social Sciences, Master's Thesis.

Egger, O., \& Rauterberg, M. (1996). Internet behaviour and addiction (Semesterthesis). Zurich: Swiss Federal Institute of Technology.

Ergin, A., Uzun, S., \& Bozkurt, A. (2013). Internet addiction prevalence and contributing factors in the medical faculty students. Pamukkale Medical Journal, 6(3), 134-142.

Esen, E. (2010). Examining psycho-social variables that predict internet addiction among adolescents. Dokuz Eylül University, Institute of Educational Sciences, Master's Thesis.

Fraenkel, J. R., \& Wallen, N. E. (2006). How to desing and evaluate research in education. New York: McGaw-Hill International Edition.

Fu, K.-w., Chan, W. S., Wong, P. W., \& Yip, P. S. (2010). Internet addiction: Prevalence, discriminant validity and correlates among adolescents in Hong Kong. The British Journal of Psychiatry, 196(6), 486-492. Available at: https://doi.org/10.1192/bjp.bp.109.075002. 
Günay, O., Öztürk, A., \& Arslantaş, E. E. (2018). Internet addiction and depression levels in Erciyes University students. Neurological Sciences, $31(1), 79-88$.

Günüç, S. (2009). Development of internet addiction scale and scrutinising the relations between the internet addiction and some demographic variables. Yüzüncü Yıl University, Institute of Social Sciences, Master's Thesis.

Hekim, Ö., Göker, Z., Aydemir, H., Çöp, E., Dinç, G., \& Üneri, Ö. (2019). Internet addiction and its relation with psychopathology in adolescents: A cross-sectional study. Turkish Journal of Clinical Psychiatry, 22(3), 329-337.

Ilhan, M., Dikmen, A., Uslu, İ., Medeni, V., Altun, B., \& Tezel, A. (2014). Internet use frequency and addiction of people over the age of fifteen in Ankara. Literature Symposium, 1(4), 34-42.

Karaman, M. K., \& Kurtoğlu, M. (2009). Preservice teachers' opinions about internet addiction. Paper presented at the Academic Informatics '09 XI. Academic Informatics Conference Papers.

Karasu, F. (2017). Examination of the relationship between the internet addiction of university students and the social support. Kilis 7 Arallk University Journal of Social Sciences, 7(14), 372-386.

Kaya, Z. (2006). Instructional technologies and material development. Ankara: PegemA Publishing.

Kaya., A. (2011). Teacher candidates' usage of social network sites and internet addiction levels. Ege University, Institute Sciences, Master's Thesis.

Kılınç, İ., \& Gündüz, Ş. (2017). Investigation of high school students' cyber sensitivity, internet addiction and humanistic values. Trakya Journal of Education, 7(2), 261-283.

Kır, G. (2008). Internet and youth. İzmir: Şenocak Publishing.

Kırık, A. M., Arslan, A., Karaman, M., \& Çetinkaya, A. (2015). Digital addiction in high school and university students. International PeerReviewed Journal of Communication and Humanities Research, 8(8), 34-58.

Kısa, Ö. (2018). Investigating the relationship between loneliness and social skills level with internet addiction of secondary school students. Kırklareli University, Institute of Health Sciences, Master's Thesis.

Kutlu, G., Turgut, M., \& Sinem, M. U. T. (2017). Determining the level of internet addiction of health management students. Journal of Politics, Economics and Management, 5(3), 63-77.

Morahan-Martin, J., \& Schumacher, P. (2000). Incidence and correlates of pathological internet use among college students. Computers in Human Behavior, 16(1), 13-29. Available at: https://doi.org/10.1016/s0747-5632(99)00049-7.

Ogel, K. (2010). Smoking, alcohol and substance use disorders: Diagnosis, treatment and prevention. İstanbul: Yeniden Publishing.

Oztoprak, M. T. (2001). Effects of computer networks on the productivity of the office workers and a research. Gazi University, Institute of Social Sciences, Master's Thesis.

Oztürk, Ö., Odabaşıŏlu, G., Eraslan, D., Genç, Y., \& Kalyoncu, O. A. (2007). Internet addiction: Clinical aspects and treatment strategies. Journal of Dependence, $8(1), 36-41$.

Poodineh, Z., Barati, F., Moghadam, M. P., Ghanbarzehi, N., \& Balouchi, A. (2016). Comparison internet addiction among students of Zahedan and Kerman Universities of medical sciences. Der Pharmacia Lettre, 8(19), $210-214$.

Sherer, K. (1997). College life on-line: Healthy and unhealthy internet use. Journal of College Student Development, 38(6), 655-665.

Sipahi, H., Kartal, E., Gökkılıç, B., Demir, H., Yoldaş, S., Yabar, S., . . Oğuz, V. (2019). Evaluation of internet addiction and safe internet use in adolescents of four schools located in Bornova district. Journal of Ege T2p, 58(4), 375-383.

Tamam, L. (2009). Impulse control disorders. Ankara: Physicians Publishing Union.

Turnalar, K. G. (2008). Examining the variables predicted internet addiction. Mersin University, Institute of Social Sciences, Master's Thesis.

Uğurlu, T. T., Sengül, C. B., \& Sengül, C. (2012). Psychopharmacology of addiction. Current Approaches in Psychiatry, 4(1), 37-50.

Yaraşır, E. (2018). Determination of internet addiction and physical activity levels in Firat University health services vocational school students. Firat University, Institute of Health Sciences, Master's Thesis.

Yılmaz, K., \& Horzum, M. B. (2005). Globalization, information technologies and university. Inönü University Journal of Education Faculty, 6(10), 103-121.

Yılmaz., D., Çinar, H. G., \& Özyazıcıoğlu, N. (2017). The examination of relationship between smart phone, internet addiction and upper extremity fuctional activity levels among nursing students. SDU The Journal of Health Science, 8(3), 34-39.

Young, K. S. (2004). Internet addiction: A new clinical phenomenon and its consequences. American Behavioral Scientist, 48(4), 402-415. Available at: https://doi.org/10.1177/0002764204270278.

Young., K. S. (1996). Internet addiction: The emergence of a new clinical disorder. Cyber Psychology and Behavior, 1(3), 237-244. Available at: https://doi.org/10.1089/cpb.1998.1.237.

Ziyalar, A. (1999). Social psychiatry (2nd ed.). İstanbul: Yüce Publications.

Zorbaz, O. (2013). Analysis of problematic internet use of high school students in terms of social anxiety and peer relations. Hacettepe University, Institute of Social Sciences, Master's Thesis. 